\title{
EDUCAÇÃO INCLUSIVA: SIGNIFICADO E REALIDADE
}

\author{
INCLUSIVE EDUCATION: MEANING AND REALITY \\ ÉDUCATION INCLUSIVE : SIGNIFICATION ET RÉALITÉ \\ EDUCACIÓN INCLUSIVA: SIGNIFICADO Y REALIDAD
}

Maria das Graças Viana Bragança *
Zélia Maria Freire de Oliveira **

\section{RESUMO}

O presente artigo, baseado em estudos bibliográficos de pesquisadores da atualidade sobre $o$ tema, discute uma abordagem mais abrangente do conceito de escola inclusiva, já que uma sociedade democrática precisa de que todos sejam incluidos com seus direitos e deveres. $E$ necessário falar da educação inclusiva, seu significado e importância no contexto social e educacional para haver educação integral para todos. Educação inclusiva é um processo que busca recolocar na rede de ensino, em todos os seus graus, as pessoas excluidas (portadoras de necessidades especiais, de distúrbios de aprendizagem ou de deficiência, excluidas por gênero, cor ou outros motivos). Apesar de várias legislaçôes a favor, pouca coisa tem sido feita em prol da educação inclusiva. Para que aconteça a educação inclusiva, é preciso a mobilização e a reflexão do setor político, da comunidade, dos pais, dos gestores de escola, dos professores, de todos os alunos, especiais ou não.

Palavras-chave: Educação inclusiva. Pessoas excluidas. Açôes afirmativas.

\footnotetext{
* Mestranda no Programa de Pós-Graduação em Educação da Universidade Católica de Brasília - UCB (graca100@terra.com.br).

** Mestranda no Programa de Pós-Graduação em Educação da UCB (zeliam@brturbo.com.br).
} 


\section{UMA NOVA EDUCAÇÃO PARA UM NOVO MUNDO}

Neste século XXI, preconiza-se a necessidade de ações para fomentar a paz e reinventar a paideia, que, segundo Platão, é a essência de toda a verdadeira educação, que dá ao homem o desejo e a ânsia de se tornar um cidadão perfeito e o ensina a mandar e a obedecer, tendo a justiça como fundamento. $\mathrm{Na}$ sua abrangência, o conceito de paideia não designa unicamente a técnica própria de preparar a criança para a vida adulta, mas o resultado do processo educativo que se prolonga por toda a vida, muito além dos anos escolares, um desenvolvimento pleno do homem. E esse desenvolvimento pleno também significa educação e cultura, e a educação não pode abrir mão da sua responsabilidade social, uma reflexão sobre a sociedade, o homem e a busca de caminhos e soluçóes para se constituir um mundo novo onde não só prevaleça a razão, mas o amor, a solidariedade; uma nova educação que deixe de ser produto para se tornar serviço (CARNEIRO, 2004).

Para o autor citado, é preciso haver escolas e universidades diferentes, com novo pensar, onde cada um se sinta pobre do outro e tenha necessidade de sentir, tocar e amar o outro para se viver em solidariedade e respeito pelo próximo. Isso vai ao encontro da idéia de escola inclusiva, foco deste artigo, que pretende discutir opiniōes de pesquisadores atuais, dando uma visão mais abrangente de seu conceito e ressaltando a necessidade do envolvimento de toda a sociedade.

\section{UM NOVO CONCEITO DE ESCOLA INCLUSIVA}

As palavras de Carneiro (2004) levam à idéia de escola inclusiva, que visa possibilitar que todas as pessoas possam participar em igualdade de oportunidades da escola. E ainda que todas as pessoas sejam respeitadas pelo que são como seres humanos, não importando o sexo, a idade, as origens étnicas, a opção sexual ou as deficiências.

No mundo atual há diferentes segmentos sociais, e muitos deles ainda lutam por seus direitos de inclusão na sociedade, como, por exemplo, o das mulheres, o dos negros, o dos sem-terras, o dos deficientes físicos, mentais, visuais, auditivos e de tantos outros excluídos. Para isso, é necessário que a sociedade seja aberta a todos e seja inclusiva; estimule a participação de cada um; valorize as diferentes experiências humanas; reconheça o potencial de todo cidadão; ofereça oportunidades iguais para que cada pessoa seja autônoma e autodeterminada e reconheça todos os seres humanos como cidadãos livres e iguais.

Embora com lentidão, muitas conquistas já aconteceram; inclusive, leis têm sido criadas para a garantia dos direitos dos excluídos, mas isso é pouco para transformar a sociedade e a escola em totalmente inclusiva. Existem muitas políticas dissimuladas de exclusão nas escolas; há grupos de pessoas discriminadas, até mesmo nas denominações que recebem: inválido, excepcional, deficiente, mongol, "down", manco, ceguinho, aleijado, demente, negro, ações preconceituosas atenuadas.

Muitas pessoas, ao tratarem do assunto 'escola inclusiva', pensam somente em pessoas deficientes, mas não só deficientes são excluídos da escola; o conceito de excluído é muito mais amplo, havendo muitos tipos de excluídos da escola. 
A chamada educação inclusiva teve início nos Estados Unidos através da Lei Pública 94.142, de 1975, e foi se expandindo. Na década de 90, no Brasil, segundo Prieto (2000), o discurso da inclusão escolar assumiu status privilegiado, persistindo, porém, muitas controvérsias a respeito do assunto. Há profissionais que defendem a inclusão escolar como parte de um movimento maior de inclusão social, sobretudo no meio educacional, pela universalização do acesso e pela qualidade do ensino; há outros que têm interpretado a inclusão escolar como mero acesso de alunos com deficiência à classe comum.

Pode-se dizer que educação inclusiva é um processo que busca recolocar na rede de ensino, em todos os seus graus, as pessoas excluídas (portadoras de necessidades especiais, de distúrbios de aprendizagem ou de deficiência, excluídas por gênero, cor ou outros motivos). A educação inclusiva diz respeito ao direito à educação e, conforme Monteiro (2004), deve basear-se em princípios tais como: a preservação da dignidade humana, a busca de identidade e o exercício da cidadania. Segundo Macedo (2005), é preciso refletir sobre os fundamentos da educação inclusiva, procurar saber e repensar o modo de funcionamento institucional, hoje pautado na lógica da exclusão em favor da lógica da inclusão.

Conforme consta na Cartilha da Inclusão dos Direitos das Pessoas com Deficiências, para se ter realmente uma sociedade democrática, é preciso criar uma nova ordem social, pela qual todos sejam incluídos no universo dos direitos e deveres (GODOY, 2000).

\section{COMO TORNAR A EDUCAÇÃO INCLUSIVA?}

A resposta a essa pergunta pode ser dada através de soluções simples e concretas para muitos, mas complexas e demoradas para tantos; exige o desejo de conhecer, de se arriscar, de se envolver e agir. Buscar essas respostas é construir uma sociedade inclusiva. Segundo Mrech (2005), o processo educativo de uma escola inclusiva deve ser entendido como um processo social, em que todas as crianças portadoras de necessidades especiais e de distúrbios de aprendizagem têm o direito à escolarização o mais próximo do normal.

A escola inclusiva deve ser uma escola líder em relação às demais escolas, segundo Almeida (2005), com padrōes de desempenho por parte de todas as crianças envolvidas, em que os professores estejam mais próximos dos alunos na captação das suas maiores dificuldades; uma escola que proporcione um maior apoio e continuidade no desenvolvimento profissional, uma rede de suporte para superação das suas maiores dificuldades, e que esteja integrada à sua comunidade, tendo os pais como parceiros. Os critérios de avaliação antigos deverão ser mudados para atender às necessidades dos alunos portadores de deficiência.

Para Monteiro (2004), a educação inclusiva "deve assegurar um conjunto de recursos e serviços educacionais, organizados institucionalmente para apoiar, complementar, suplementar e até substituir os serviços educacionais comuns, garantindo o atendimento às diferenças dentro da diversidade humana". Diz ainda a autora que o compromisso dos educadores deve ser garantir a educação escolar e promover o desenvolvimento pleno do indivíduo, em todos os níveis, etapas e modalidades da educação. 
Para que haja educação inclusiva são necessárias várias ações na escola, na sociedade, na família, como: melhor investimento na formação do professor, proporcionando-lhe meios criativos para que elabore planejamentos eficazes para as aulas e desenvolva a percepção das diferenças e das possibilidades das pessoas com deficiência, aprendendo a lidar com necessidades e alternativas; adaptaçôes na escola, conforme estipulam as leis que amparam os deficientes, facilitando-lhes o acesso; assistência à saúde; qualificação profissional; estímulo e facilidade à prática de esporte; cultura e lazer; prática de ética, moral, religião, amor ao próximo.

Segundo Mantoan (2005), para haver um projeto escolar inclusivo são necessárias mudanças nas propostas educacionais da maioria das escolas, uma nova organização curricular idealizada e executada pelos seus professores, diretor, pais, alunos e todos os que se interessam pela educação na comunidade onde está a escola. Para ela, a escola inclusiva caracteriza-se por ter a progressão no ensino de forma sincrônica e organizada em ciclos de formação e de desenvolvimento, e não serial e linear, como acontece nas escolas.

É preciso saber como vivem as pessoas com deficiência, conhecer suas expectativas, necessidades e alternativas, para que se possa realmente pensar nas dificuldades e conquistas desses excluídos e na possibilidade de concretização dos seus direitos (GODOY, 2000).

\section{AS AÇÕES AFIRMATIVAS}

As ações afirmativas fazem parte de exemplos que abrem caminhos para a igualdade de oportunidades, direitos humanos para todos.

Gomes (2001, p. 40) define as ações afirmativas:

como um conjunto de políticas públicas e privadas de caráter compulsório, facultativo ou voluntário, concebidas com vistas ao combate à discriminação racial, de gênero e de origem nacional, bem como para corrigir os efeitos presentes da discriminação praticada no passado, tendo por objetivo a concretização do ideal de efetiva igualdade de acesso a bens fundamentais como a educação e o emprego.

Somente na última década do século passado é que começaram a ser tratadas, no Brasil, pelos governos, estadual, federal e municipal. Antes desse período, as discussōes limitavam-se aos simpatizantes pela causa, aos estudiosos do assunto como antropólogos, sociólogos e historiadores e aos militantes do Movimento Negro, embora a luta desse movimento date dos meados do século XVI. Foi por ocasião das comemorações do tricentenário da morte de Zumbi, em 20 de novembro de 1995, que alcançou maior representatividade, tanto no meio político, como na sociedade civil. Nessa data, o Movimento Negro Unificado (MNU) realizou um ato de protesto que ficou conhecido pelo nome de Marcha Zumbi dos Palmares contra o Racismo, pela Cidadania e a Vida, ocasião em que os organizadores do movimento entregaram ao então Presidente da República, Fernando Henrique Cardoso, um documento falando sobre a situação do negro e um programa de ações para combate ao racismo e às desigualdades raciais no país 
(JACCOUD, 2002, p. 19). Dentre as mais diversas reivindicaçōes, dois itens constantes no MNU eram específicos sobre a educação: "Recuperação, fortalecimento e ampliação da escola pública, gratuita e de boa qualidade; desenvolvimento de ações afirmativas para o acesso dos negros aos cursos profissionalizantes, à universidade e as áreas de tecnologia de ponta". Após essa marcha, as reivindicaçôes da população negra passaram a contar com o apoio do governo federal. O fato de maior relevância, entretanto, foi a III Conferência Mundial contra o Racismo, a Discriminação Racial, Xenofobia Intolerância Correlata, realizada em Durban em 2001. Segundo Carvalho (2002), nessa conferência o governo brasileiro admitiu abertamente a existência de discriminação racial no país, e por isso várias ações afirmativas começaram a ser implementadas, como resposta às demandas da sociedade e à comunidade internacional, agora consciente da desigualdade racial existente no país. Antes da realização da III Conferência de Durban, já se encontravam em tramitação, na esfera do poder legislativo, vários projetos de leis que beneficiariam a população negra, a exemplo do PL n. 3.198 de 2000, de autoria do então deputado e hoje senador, Paulo Paim, que propõe a criação do Estatuto da Igualdade Racial, em cujo Capítulo II, art. 11 está prevista a adoção de cotas para negros no ensino público e privado; em todos os demais poderes foram criadas leis com a finalidade de dar sustentação legal às ações que estão sendo propostas. Mas foi com a III Conferência que o número de leis criando benefícios para a população negra aumentou. No âmbito do poder executivo, há o Decreto 4.886, de 20 de novembro de 2003, que trata da Política Nacional de Promoção da Igualdade Racial - PNPIR; nesse Decreto, no item II, onde são tratados os objetivos específicos sobre a educação, encontra-se a parte que trata das ações afirmativas, com a indicação para adoção de cotas nas universidades e no mercado de trabalho. As universidades começaram então a adotar a política de cotas.

Para Gomes (2001), o que tem gerado muita polêmica é a forma como as ações afirmativas têm sido implementadas. Essas açôes não têm apenas o objetivo de coibir a discriminação, mas também possibilitar a implantação de uma maior representatividade dos grupos minoritários nos diversos campos de atividade, tanto públicos como privados. Pretende-se, ao adotá-las, ajudar as vítimas a atingir objetivos notadamente inalcançáveis, se o combate à discriminação se limitasse às leis meramente proibitivas.

Para Sowell (2004), pesquisador americano, as açōes afirmativas, por razōes altamente discrepantes, têm sido aplicadas em sociedades diferentes com programas que compartilham características muito semelhantes e freqüentemente levam a resultados muito parecidos. Alguns grupos preferenciais existem para minorias, outros para maiorias. Atualmente, os programas para os menos privilegiados é que são chamados de ações afirmativas nos Estados Unidos; de "discriminação positiva" na Grã-Bretanha e na Índia; de "padronização" no Sri Lanka; "refletindo o lado federal do país" na Nigéria; "filhos do solo" na Malásia e Indonésia e também em alguns estados na Îndia. Grupos preferenciais também existem em Israel, China, Austrália, Brasil, entre outros.

Sowell (2004) diz que, apesar de serem bastante variados os motivos de se estabelecerem grupos preferenciais e cotas em alguns países do mundo, a lógica de seus incentivos tende a produzir conseqüências parecidas em sociedades totalmente diferentes. Tanto os incentivos quanto as conseqüências tendem a ser ignoradas nas discussões políticas, que se preocupam em justificar as políticas preferenciais e enaltecer seus benefícios, ignorando 
totalmente os resultados práticos delas. Ninguém se preocupa em estudar os fatos históricos. Porém, o que as políticas de grupos preferenciais fizeram em alguns países foi gerar um desconforto entre diferentes grupos da sociedade, além de não atingirem os objetivos para os quais foram criadas.

Tal pesquisador, que é contrário à adoção de tais políticas, diz que, embora tenham se tornado um fato comum, os programas de ações afirmativas são vistos como algo indesejável pelas próprias pessoas que as promovem. Ainda para ele, apesar de essas pessoas apregoarem que tais programas são temporários, essas políticas não só têm persistido como aumentado. Reafirma ainda que esses sentimentos subjetivos influenciam as políticas; mesmo onde há dados estatísticos adequados sobre o progresso de grupos que receberam tratamento preferencial, determinar quanto tal progresso resultou de políticas preferenciais e não de outros fatores continua sendo um desafio.

Sowell (2004) ainda ressalta que o padrão errôneo dos beneficiários dos programas de ação afirmativa deveria suscitar o questionamento da premissa na qual a ação afirmativa se baseia; a premissa é de que uma distribuição desigual de renda e emprego indica intençôes discriminatórias para com os menos afortunados, o que deve ser contrabalançado com políticas preferenciais. Porém, quando essas políticas bem intencionadas demonstram o mesmo padrão errôneo do que elas deveriam combater, fica difícil não concluir que algo mais do que intenção deve ser levado em conta; deve-se analisar quem é a vítima e quem não é.

Ainda para o autor citado, as disparidades estatísticas não provam nada sobre discriminação, porque elas são comuns mesmo em situações em que os dominantes estatisticamente não têm como discriminar. A culpa dos poucos benefícios da ação afirmativa, principalmente para os que são realmente necessitados, normalmente, recai na falta de zelo ou mesmo na má-fé dos administradores de programas.

A ação afirmativa também pode ser "soma negativa" quando membros de grupos não preferenciais se retiram da sociedade, privando-a de sua contribuição, como, por exemplo, na África após o "apartheid"; com a ação afirmativa para os negros, muitos trabalhadores brancos do governo se aposentaram mais cedo e milhares deles emigraram a cada ano (SOWELL, 2004).

Inúmeras teorias, premissas e princípios têm sido usados para justificar programas de ação afirmativa - alguns são comuns em todo o mundo, outros são peculiares a certos países ou comunidades. O que é impressionante é que raramente essas noções são testadas empiricamente ou são definidas de forma clara ou lógica, ou mensuradas de acordo com as consequiências dolorosas que irão gerar. Se as pessoas observassem as conseqüências reais dessas políticas, certamente não encontrariam nenhum argumento a favor delas, a não ser que considerassem que qualquer reparação social, mesmo pequena, compensa quaisquer custos ou perigos, mesmo grandes.

Na opinião de Walters (1996, p. 121) "as ações afirmativas, em conjunto com outros mecanismos, têm auxiliado não somente na ampliação das oportunidades igualitárias e na promoção da inclusão, mas, acima de tudo, elas têm ajudado a criar uma sociedade mais democrática”. Fazem também com que se perceba a existência de um princípio e a disposição de meios que auxiliem uma sociedade a adquirir um balanço socioeconômico melhor das condições necessárias. Para ele, aqueles que são contra tais 
medidas argumentam pela perpetuação dos desequilíbrios e, talvez, pela perpetuação da instabilidade social.

Vieira (2003, p. 93) sugere que algumas reflexões devem ser feitas no que se refere à adoção de um modelo de ação afirmativa no Brasil, que não deve adotar como parâmetro o dos EUA, porque o Brasil trilha em caminho oposto; decorre disso que cabe igualmente investir no estudo das características das relações Estado/sociedade no Brasil, pois estas, historicamente construídas no confronto entre momentos de autoritarismo e de participação democrática, tornaram a luta social peculiar no Brasil e seus reflexos podem ser encontrados na independência da sociedade civil, na implementação de ações afirmativas.

Conforme Carvalho (2002) e Munanga (2003), a situação dos povos indígenas, em termos de exclusão em relação ao ensino, em todos os níveis, é visível, e açōes de inclusão de indígenas são poucas. Algumas atitudes têm sido tomadas, como alguns convênios firmados com universidades e a realização do projeto Tucum de formação e capacitação de professores indígenas, em nível de magistério, para as comunidades de Mato Grosso (Xavantes, Paresi, Apiaka, Irantxe entre outros).

\section{A EDUCAÇÃO INCLUSIVA E A ESCOLA DE QUALIDADE}

Como há um cruzamento entre o movimento da educação inclusiva e a busca de uma escola de qualidade para todos, é relevante a pesquisa feita por Casassus (2002), na América Latina. Casassus direcionou a atenção para a desigualdade educacional e as possíveis soluções para superá-la, analisando os fatores socioeconômicos e socioculturais; função de produção (relativo aos fatores internos à escola) e a análise multinível, que permitia ver os impactos dos fatores internos e externos à escola no sucesso. Ao final de um longo trabalho, concluiu que os estudantes com contextos familiares diferentes têm resultados desiguais e que o status sociocultural dos pais tem um peso bastante significativo. Quanto aos fatores internos à escola, o autor constatou que o mais significativo é o clima emocional existente na aula, que tem um impacto muito grande nos resultados escolares.

Segundo Casassus (2002), as reformas educacionais foram estruturadas tomando-se por base o modelo insumo-produto, e este estava direcionado para melhorar a qualidade da educação e não para superar a desigualdade, e após dez anos de reforma, houve apenas uma pequena melhoria no rendimento escolar, mas a distância entre as escolas permanece. Para ele, as escolas bem-sucedidas e que favorecem um melhor desempenho têm: disponibilidade de materiais didáticos e recursos na biblioteca, autonomia profissional, tanto na gestão quanto na docência; formação inicial pós-médio dos professores; poucos alunos por professor na sala de aula; avaliação de forma sistemática; a comunidade envolvida e um ambiente emocional favorável à aprendizagem. Dentre essas características, duas têm um significado maior sobre o ponto de vista de uma escola inclusiva: trata-se da não-existência de nenhum tipo de segregação, seja intelectual, racial ou de gênero, a cultura fomentando a diversidade e a aceitação do outro; a outra característica trata do ambiente emocional que favorece a aprendizagem e o peso que este tem sobre os demais. Essas duas variáveis, sob o ponto de vista de uma escola inclusiva, 
favorecem muito os seus atores. Tem-se, portanto, as variáveis que qualificam uma escola inclusiva: se os responsáveis pela sua gestão conseguirem colocá-las em prática, num futuro próximo, as crianças que estiverem ingressando nesse novo sistema de ensino só irão tomar conhecimento da política de ação afirmativa, cotas para negros e índios no ensino superior através da literatura. Se elas são colocadas em prática, num sentido positivo e de maneira articulada entre si, as possibilidades de melhores desempenhos dos meninos e meninas serão potencializadas, e os impactos negativos da desigualdade estrutural serão atenuados, reduzindo-se, desta forma, a distância entre os que têm e os que não têm (CASASSUS, 2002, p. 157).

Castro (1999) apresentou um estudo do comportamento dos indicadores educacionais na década de 90 e fez um balanço da situação educacional do país, o que está sendo feito tanto na área federal como na estadual e municipal para a melhoria do ensino no Brasil. "A liderança do governo federal no campo das políticas de promoção da eqüidade e da qualidade do sistema educacional somente foi assumida com maior desenvoltura na década de 90, consolidando-se nos últimos quatro anos", segundo Castro (1999, p. 18). Os Estados e os Municípios se tornaram importantes atores na formulação e implementação dessas políticas, ficando o Ministério de Educação e Cultura - MEC, com papel de articulador e monitor dessas políticas. Ainda para Castro (1999), o governo passou a adotar sistemas nacionais de avaliação e indicadores educacionais para todos os níveis de ensino e deixou de ser executor direto de açōes, principalmente na área de educação básica. $\mathrm{Na}$ área de avaliação, houve uma importante mudança cultural entre gestores e dirigentes dos sistemas de ensino, que passaram a considerar os processos avaliativos externos às escolas como um instrumento importante para o monitoramento das políticas. Castro (1999, p. 17) aponta várias políticas adotadas para a melhoria da qualidade da educação básica: o aperfeiçoamento metodológico e a consolidação do Sistema Nacional de Avaliação da Educação Básica (Saeb); a avaliação pedagógica qualitativa dos livros didáticos e a elaboração e distribuição do "Guia de Avaliação do Livro Didático"; a discussão, formulação e divulgação de referenciais e metas de qualidade por meio dos Parâmetros Curriculares Nacionais (PCNs) para o ensino fundamental. Fala também das ações que vêm sendo promovidas pelo governo brasileiro, procurando construir um sistema de ensino com qualidade e com eqüidade, por estabelecimento do Fundo de Manutenção e Desenvolvimento do Ensino Fundamental e de Valorização do Magistério (Fundef), do Censo Educacional e do Sistema Nacional de Avaliação da Educação Básica (Saeb).

\section{CONCLUSÃO}

É fundamental a reflexão nos meios políticos, educacionais e sociais sobre a educação inclusiva, a que ela pode levar, como e por quem pode ser construída.

Segundo Prieto (2000), a inclusão é uma possibilidade que se abre para o aperfeiçoamento da educação escolar e para o benefício de todos os alunos com e sem deficiência; ensinar é marcar um encontro com o outro, e a inclusão escolar provoca, basicamente, uma mudança de atitude diante do outro, esse que é alguém especial e que requer do educador ir além. 
Para Monteiro (2004), a inclusão de alunos que apresentam necessidades educacionais especiais na rede regular demanda não apenas a matrícula do aluno ou a permanência física junto com aqueles considerados normais, mas a oportunidade de serem revistas concepções e paradigmas, num profundo respeito pelas suas diferenças, para se aprender a conviver com as diferenças, o que é uma das maiores dificuldades da humanidade. Diz ainda que, para atender às diferenças e às necessidades especiais, é preciso mudar o olhar da escola, pensando não a adaptação do aluno, mas a adaptação do contexto escolar aos alunos, romper barreiras humanas e arquitetônicas, "criando novos conceitos, dando novos sentidos, ressignificando a aprendizagem e, conseqüentemente, o desenvolvimento humano".

Quanto às ações afirmativas, as opiniões dos estudiosos são conflitantes quanto à

eficiência ou não dessas políticas. Enquanto Sowell declara-se, veementemente, contra a adoção dessa política, que para ele só tem gerado mais discriminação nos países que a adotaram, outros vêem tal política como sendo positiva e necessária. Para vários pesquisadores brasileiros, as medidas são necessárias e benéficas, com função reparadora e inclusiva, pois funcionam como um instrumento de promoção de eqüidade para as minorias negras e indígenas.

Casassus, em sua pesquisa, aponta caminhos a serem seguidos por uma escola inclusiva que deriva de uma escola sem desigualdades e que tem a eqüidade como meta.

Há diversos caminhos para se fazer uma educação inclusiva, devendo a escola e a comunidade eleger as melhores formas, observando pesquisas e estudos a respeito e fazendo as modificações que forem necessárias para que o processo de educação inclusiva realmente aconteça. Conforme Freitas (2002), uma escola para todos somente será realidade quando a escola for, além de um local de aprendizagem, um local de tomada de consciência e de luta contra as desigualdades sociais.

\section{Referências}

ALMEIDA, Marina da Silveira Rodrigues. Manual informativo sobre inclusão informativo para educadores. Disponível em:

www.educacaoonline.pro.br/art_manual_informativos.asp?f_id_artigo. Acesso em: 15 mar. 2005. CARNEIRO, Roberto. Aprender a educar no século XXI. 2004. Palestra proferida no Seminário dos 10 anos do Mestrado em Educação da UCB, Brasília, 2004. Não publicado.

CARVALHO, José Jorge; SEGATO, Rita Laura. Uma proposta de cotas para estudantes negros na Universidade de Brasília. Brasília: UnB, mimeografado (versão revisada e ampliada), mar. 2002.

CASASSUS, Juan. A escola e a desigualdade. Brasília: Plano, 2002.

CASTRO, Maria Helena Guimarães de. A educação para o século XXI: o desafio da qualidade e da eqüidade. Brasília: Inep, 1999. Disponível em: www.inep.gov.br. Acesso em: 17 nov. 2004.

FREITAS, Luiz Carlos. A internalização da exclusão. Educação e Sociedade. Campinas: Cedes, v. 23, n. 80, p. 229-325, set. 2002. ISSN 0101-7330.

GODOY, Andréa et al. Cartilha da inclusão dos direitos das pessoas com deficiência. Belo Horizonte: PUC Minas, 2000. 
GOMES, Joaquim Benedito Barbosa. Ação afirmativa \& princípio constitucional da igualdade (O Direito como instrumento de transformação social: a experiência dos EUA). Rio de Janeiro: Renovar, 2001.

JACCOUD, Luciana; BEGHIN Nathalie. Desigualdades raciais no Brasil: um balanço da intervenção governamental. Brasília: Ipea, 2002.

MACEDO, Lino. Fundamentos para uma educação inclusiva. Disponível em: www.educaçãoonline. pro.br/art_fundamentos_para_educação_inclusiva.asp?f_id_artigo. Acesso em: 20 mar. 2005.

MANTOAN, Maria Teresa Eglér. Uma escola de todos, para todos e com todos: o mote da inclusão. Disponível em: www.lite.fae.unicamp.br/papet/2002/nt/ta1.5.htm. Acesso em: 20 maio 2005.

MONTEIRO, Mariângela da Silva. Ressignificando a educação: a educação inclusiva para seres humanos especiais. Disponível em: www.educacaoonline.pro.br. Acesso em: 15 mar. 2004.

MRECH, Leny Magalhães. $O$ que é educação inclusiva? Disponível em: www.educacaoonline.pro.br/art_a_onda_inclusiva.asp?f_id_artigo. Acesso em: 20 mar. 2005.

MUNANGA, Kabengele. Políticas de ação afirmativa em benefício da população negra no Brasil: um ponto de vista em defesa de cotas. Revista Espaço Acadêmico, v. 2, n. 22, mar. 2003. Disponível em: www.espacoacademico.com.br/. Acesso em: 22 maio 2005.

PRIETO, Rosângela Gavioli. Políticas públicas de inclusão: compromissos do poder público, da escola e dos professores. São Paulo: Cortez, 2000.

SOWELL, Thomas. Affirmative action around the world: an empirical study. New Haven: Yale University Press, 2004.

VIEIRA, Andréa Lopes da Costa. Política de educação, educação como política: observações sobre a ação afirmativa como estratégia política. In: SILVA, Petronilha Beatriz Gonçalves; SILVÉRIO, Valter Roberto (Orgs.). Educação e açôes afirmativas: entre a injustiça simbólica e a justiça econômica. Brasília: INEP, 2003. p. 83-97.

WALTERS, Ronald. Racismo e ação afirmativa. In: SOUZA, Jessé (Org.). Multiculturalismo e racismo: o papel da ação afirmativa nos estados democráticos contemporâneos. Brasília: Ministério da Justiça, 1996. p. 105-121. 


\section{Inclusive education: meaning and reality}

Abstract

To have an integral education for all, it is necessary to talk about inclusive education, its meaning and importance in the social and educational context. Inclusive education is a process that tries to reintegrate within the school system, at all levels, the excluded persons (excluded on account of learning disabilities or identified as handicapped, excluded because of gender or color or many other reasons). It is a social process that requires the mobilization of the political sector, the community, the parents, the school managers, the teachers and all of the students, handicapped or not. In spite of several laws in favor, not much has been done to make inclusive education happen. An example is affirmative actions. To have a really democratic society, it is necessary to create a new social order through which all may be included in the universe of rights and duties.

Keywords: Inclusive education. Excluded persons. Affirmative actions.

\section{Éducation inclusive : signification et réalité \\ Résumé}

Pour avoir une éducation intégrale pour tous, il faut parler de l'éducation inclusive, de sa signification et de son importance dans le contexte social et éducationnel. L'éducation inclusive est un processus qui cherche à reintégrer dans le système d'enseignement, à tous ses niveaux, les personnes excluées (excluées parce ce qu'elles sont handicappées ou ont des problèmes d'appentissage ou des déficiences, excluées par son genre, sa couleur ou beaucoup d'autres motifs). C'est un processus social qui requiert la mobilisation du secteur politique, de la communauté, des parents, des gestionnaires de l'école, des maîtres, de tous les élèves, porteurs de déficiences ou non. Malgré les différentes lois à faveur, peu a été fait pour que l'éducation inclusive se réalise. Un exemple sont les actions affirmatives. Pour avoir une société réellement démocratique, il faut crier une nouvelle ordre sociale, à travers de laquelle tous soient inclus dans l'univers des droits et des devoirs.

Mots clefs : Education inclusive. Personnes excluées. Actions affirmatives.

\section{Educación inclusiva: significado y realidad}

\section{Resumen}

El presente artículo, basado en estudios bibliográficos de pesquisadores de la actualidad acerca del tema, discute un abordaje más amplio del concepto de escuela inclusiva, ya que una sociedad democrática necesita que todos sean incluidos con sus derechos y deberes. Es necesario hablar de la educación inclusiva, su significado e importancia en el contexto social y educacional para que haya educación integral para todos. Educación inclusiva es un proceso que intenta reponer en la red de enseñanza, en todos sus grados, las personas excluidas (portadoras de necesidades especiales, de disturbios de aprendizaje o de deficiencia, excluidas por género, color u otros motivos). A pesar de varias legislaciones a favor, poco ha sido hecho en prol de la educación inclusiva. Para que ocurra, es necesario la mobilización y la reflexión del sector politico, de la comunidad, de los padres, de los gestores de escuela, de los profesores, de todos los alumnos, especiales o no.

Palabras-clave: Educación inclusiva. Personas excluidas. Acciones afirmativas.

Recebida I a versão em: 07.06.2005

Aceita $2^{\mathrm{a}}$ versão em: 20.12.2005 
228 